\title{
Critical Discourse Analysis of Sino-U.S. News Reports on Trade War: A Corpus-based Comparative Study
}

\author{
Wang Liyang*, Wang Jiayi, Luo Qian \\ College of Foreign Languages, Hunan Institute of Engineering, Xiangtan, China \\ Email address: \\ 380510141@qq.com (Wang Liyang), boriswjy@163.com (Wang Jiayi),1850393436@qq.com (Luo Qian) \\ ${ }^{*}$ Corresponding author
}

To cite this article:

Wang Liyang, Wang Jiayi, Luo Qian. Critical Discourse Analysis of Sino-U.S. News Reports on Trade War: A Corpus-based Comparative Study. English Language, Literature \& Culture. Vol. 5, No. 3, 2020, pp. 84-90. doi: 10.11648/j.ellc.20200503.12

Received: July 20, 2020; Accepted: August 5, 2020; Published: August 10, 2020

\begin{abstract}
Since April 2018, the U.S. government headed by U.S. President Trump has adopted trade protection measures, and the Sino-U.S. trade war broke out. This lasting event has attracted widespread attention from domestic and foreign media, and the attitudes and opinions presented by various reports are different. In order to explore more in-depth information behind news reports, we analyze the Sino-U.S. trade war news based on the collected corpora. By combining corpus analysis and Fairclough's three-dimensional analysis framework of Critical Discourse Analysis (CDA) and collecting 15 news reports on the websites of China Daily and The Wall Street Journal respectively from January 2019 to January 2020, this study explores the focuses of Sino-U.S. reports and their attitudes towards Sino-U.S. trade issues, and further reveals the national images of the two countries constructed by the media. It is found that the Wall Street Journal reports focus on the tariff policies and the economic impact of the Sino-U.S. trade war on its own country. While China Daily reports focus on response to trade war. For building a national image, The Wall Street Journal uses more positive words to construct the United States as an image of strong and just. China Daily builds China as an image of a big country that actively responded to challenges and actively promoted global free trade and peaceful coexistence. This study provides some empirical evidence for the critical discourse analysis of news discourse, deepens our understanding of the ideology hidden behind the news discourse, and has a certain enlightening role for discourse analysis of different genres.
\end{abstract}

Keywords: Corpus Research, Critical Discourse Analysis, Sino-U.S. Trade War

\section{Introduction}

China and the United States are not only the two largest economies in the world, but also the top two trading powers in the world in terms of trade volume. Since April 2018, the U.S. government, led by U.S. President Trump, has insisted on adopting trade protection measures, and launched a trade war against China. This protracted war has attracted widespread attention from domestic and foreign media. But affected by many factors such as specific political and economic policies, social and cultural backgrounds and ideology, news discourses often imply the positions and attitudes of the media. Critical Discourse Analysis is an effective way to analyze news texts, which can explore the relationship and role between discourse, power relations and ideology from the superficial language form. Corpus-based Critical Discourse Analysis can take advantage of combining quantitative and qualitative research to reduce the impact of researchers' subjective bias on research and enhance the objectivity of research. This paper makes a Critical Discourse Analysis of the Sino-U.S. trade war reported by China Daily and The Wall Street Journal, to explore the similarities and differences between the focuses on the Sino-U.S. trade war reports from different media and the construction of discourse subjects, and compare the ideologies behind the news, so as to better understand the position and differences of Sino-U.S. news reports.

\section{Literature Review}

\subsection{Critical Discourse Analysis}

Critical Discourse Analysis is an effective method to reveal the relationship between ideologies and power in news discourse. It differs from other discourse research methods 
because it is deeply rooted in the critical paradigm that emphasizes social cultural analysis [1]. Critical Discourse Analysis began in 1979 and was proposed in Language and Control written by Fowler et al. [2]. Through using Critical Discourse Analysis, linguists revealed the dialectical relationship among language, power, and ideologies behind it. News reflects social ideologies. Therefore, it is the focus of Critical Discourse Analysis. As the research scope of Critical Discourse Analysis is wide and its research methods are diverse, the analysis methods adopted by critical discourse analysts are also different. For example, the dialectical-relational analysis method proposed by Fairclough [3], the discourse-historical method proposed by Wodak, R. et al. [4] and the social-cognitive method proposed by Van Dijk [5]. However, Widdowson (1995) questioned the objectivity of Critical Discourse Analysis due to personal views on discourse and pointed that the authority of interpretation process and conclusions are difficult to guarantee [6]. Therefore, corpus technology can show objective facts to the greatest extent and enable researchers to overcome intuitive deviations, thus ensuring the objectivity of the research. Hardt-Mautner (1995) is the first scholar to advocate the combination of Critical Discourse Analysis and corpus method. He believed that the powerful search function of corpus can support qualitative research on a large number of texts [7]. Baker et al. (2013) perfected the analysis framework combining the corpus and Critical Discourse Analysis after a large amount of empirical research, marking the maturity of this method [8]. In recent years, more and more scholars at home and abroad have used corpus method for Critical Discourse Analysis, and the combination of the two has also achieved fruitful results.

\subsection{Corpus Based Language Research}

Corpus usually refers to the language materials collected for language research and stored in electronic form, which are collected from natural written or spoken language samples. A corpus with appropriate scale can describe the usage of language. The corpus takes real language data as the research object, analyzes the language facts from a macro perspective, and finds the rules of language use [9]. In recent years, the field of corpus research has been continuously expanded. Combining with the reality of corpus research, the research field of corpus is divided into five aspects: linguistics, translation, metaphor, discourse analysis and second language acquisition. Corpus Linguistics Approach (CLA) is a new research perspective, which is often used for Critical Discourse Analysis [10]. The relevant research combining corpus with Critical Discourse Analysis mainly includes: Baker, P., et al. [11], Bednarek, M., et al [12], Chang Baoli [13], Zhang Junchen [14], etc. Baker, P., et al. (2008) combined corpus and Critical Discourse Analysis to study the discourse representation of refugees and asylum seekers in British newspapers from 1996 to 2006. Bednarek, M., et al (2014) used multimodal news as corpus, combined corpus and Critical Discourse Analysis theory to find out utterances that can reflect ideologies, and established a research model of news discourse attitude. Chang Baoli (2019) based on the theory of systemic functional grammar, made Critical Discourse Analysis of Trump's speech at the 73rd general debate of the United Nations in 2018. Zhang Junchen (2019) used Norman Fairclough's three-dimensional frame analysis method based on a corpus to study Chinese and American English news reports that the U.S. President Trump visited China in 2017.

To sum up, Critical Discourse Analysis with corpus method is popular among scholars home and abroad. Fairclough's three-dimensional analysis model refers to discourse analysis from three frame works of text, discourse practice and social practice, which mainly studies the relationship among language, power and ideologies through discourse formation. Therefore, this paper combines Fairclough's three-dimensional analysis framework with the quantitative analysis of corpus to explore the ideology and power relationship hidden in the news. For the comparative analysis of Chinese and foreign news reports, the combination of corpus can make up for researchers' subjective bias in Critical Discourse Analysis. It pays attention to both the depth of qualitative analysis and the objectivity of quantitative analysis of the discourse.

\section{Research Methods}

The data used are news reports of the Sino-US trade war, collected from website of China Daily (www.chinadaily.com.cn) and The Wall Street Journal (www.wsj.com). China Daily is the earliest national English-language website in China. It has become a national comprehensive media website and the most influential English portal in China. The Wall Street Journal is the most influential daily newspaper in the United States and the world, focusing on financial and business reports. It was founded in 1889. The daily circulation reaches 2 million copies. These two news portals have a great influence in the world. The main consideration to use the two news portals as the source of data collection is that as the most influential newspaper, the news reports on them reflect the political, social and economic policies and ideologies of the state, and therefore, the analysis of the data is expected to have a faithful reproduction of the national identities intended by the state and their underlying political, social and economic factors.

By using "trade war" as a keyword, we searched on the website of China Daily and The Wall Street Journal, ranging from January 2019- January 2020. After a careful reading, we finally selected 15 news reports respectively. In order to prevent errors in retrieval, we manually proofread the example reports to ensure the accuracy of the corpus. Among them, China Daily Corpus contains 13,553 tokens and 2,352 types. The Wall Street Journal Corpus contains 8,734 tokens and 2,105 types. The corpus software Antconc 3.5.8 is used to present the data from three aspects: high-frequency word list, collocation and concordance line, so as to make a comparative analysis of the relevant reports in China Daily and The Wall Street Journal. 


\section{Results and Discussion}

\subsection{Different Focuses of Sino-U.S. News Reports}

High-frequency words are retrieved to analyze the focuses of Sino-U.S. news reports according to the word frequency. Language researchers can recognize some of the basic linguistic features according the high-frequency words information provided by corpus, which often contains important discourse meaning. Through the results of Table 1 and Table 2, we analyze the first 15 high-frequency content words of the two corpora. It can be found that "China", "Chinese", "trade", "economy", and "growth" are the common high-frequency words of Chinese and American media. Through the common high-frequency words, it is obvious that China is the focus by the Sino-U.S. media, including Chinese economy, trade and the Chinese government. And both sides are concerned about the trade war and its impact on the economic development of various countries to a certain extent. From the high-frequency words "growth", "we", "global" and "world" in Table 1, we can see that China regards the world as a community and takes more account of the development and interests of the partners when facing challenges. "US" shows that China pays close attention to the U.S. side in the process of trade war. On the contrary, in Table 2, the high-frequency words "tariffs", "growth", "companies" and "goods" in The Wall Street Journal reflect that the United States is more concerned about the tariff policies proposed by the government and the measures taken for the trade war and the economic development of the country. "Trump and President" reflects that the United States pays more attention to the progress of the U.S. president's cabinet on the Sino-U.S. trade agreement.

Table 1. Statistical results of high-frequency words in China Daily.

\begin{tabular}{|c|c|c|c|c|c|c|c|c|}
\hline Rank & Freq. & Words & Rank & Freq. & Words & Rank & Freq. & Words \\
\hline 1 & 196 & China & 6 & 55 & we & 11 & 38 & world \\
\hline 2 & 154 & Us & 7 & 49 & Chinese & 12 & 35 & economic \\
\hline 3 & 88 & trade & 8 & 39 & global & 13 & 33 & market \\
\hline 4 & 70 & growth & 9 & 38 & economy & 14 & 32 & said \\
\hline 5 & 68 & percent & 10 & 38 & war & 15 & 32 & year \\
\hline
\end{tabular}

Table 2. Statistical results of high-frequency words in The Wall Street Journal.

\begin{tabular}{|c|c|c|c|c|c|c|c|c|}
\hline Rank & Freq. & Words & Rank & Freq. & Words & Rank & Freq. & Words \\
\hline 1 & 114 & China & 6 & 49 & trump & 11 & 33 & year \\
\hline 2 & 106 & trade & 7 & 43 & more & 12 & 31 & companies \\
\hline 3 & 67 & said & 8 & 36 & billion & 13 & 28 & economy \\
\hline 4 & 65 & Chinese & 9 & 33 & growth & 14 & 28 & goods \\
\hline 5 & 58 & tariffs & 10 & 33 & president & 15 & 27 & talks \\
\hline
\end{tabular}

\subsection{Different Semantic Features and Attitudes of Sino-U.S. News Reports}

The collocation of "trade" is retrieved to analyze the semantic features and attitudes of Sino-U.S. news reports. Semantic analysis of collocations is helpful to deepen vocabulary understanding and reveal ideologies. Corpus linguist Stubbs explained semantic prosody and divided it into three types: positive semantic prosody, negative semantic prosody, neutral semantic prosody [15]. This paper analyzes the collocation of keywords based on the interpretation of semantic prosody by Stubbs. In Table 3, we can see that the collocation of "trade" in China Daily has both positive and negative meanings. For example, "winning trade" and "trade organization" reflect that what China pursues is mutual benefit and win-win cooperation in Sino-U.S. trade and joint maintenance of economic stability and development. "Trigger" indicates that the trade war is initiated by the United States, and "unwanted trade", "unnecessary trade", and "unilateralism trade" express that the trade war is unnecessary and was only caused by trade protectionism, which was not what China expects. Even so, China will have the ability and confidence to face the challenges. "Weighted", "undermined", "stunting" and "tough" show that the trade war has had a certain adverse impact on the economy of China and the United States, weakening the growth potential of the global economy. "Trade surplus" reflects that China has made great efforts to promote industrial upgrading and enhanced hard power in recent years. China has gradually transformed itself into an economic power, causing a trade surplus to the United States and threatening the United States' global status, which may also be the reason why the United States provokes a trade war. However, the Sino-U.S. trade deficit is a systemic economic issue, determined by the economic structure and international division of labor between China and the United States. It is a spontaneous result of the market and cannot blame China for all responsibilities. In Table 4, The Wall Street Journal often uses negative words to describe trade, such as "worsening", "turbulent", "vicious", “weakness", "thornier", etc., indicating that the American media are more concerned about the economic impact of trade war, reflecting that the American economy has caused great losses. 
Table 3. List of collocations of "trade" in China Daily.

\begin{tabular}{llllllllllll}
\hline Rank & Freq & Freq (L) & Freq (R) & Stat & Collocate & Rank & Freq & Freq (L) & Freq (R) & Stat & Collocate \\
\hline 1 & 2 & 1 & 1 & 8.27221 & winning & 14 & 2 & 1 & 1 & 7.27221 & unnecessary \\
2 & 2 & 1 & 1 & 8.27221 & surplus & 15 & 1 & 1 & 0 & 7.27221 & unilateralism \\
3 & 2 & 1 & 1 & 8.27221 & office & 16 & 1 & 1 & 0 & 7.27221 & undermined \\
4 & 2 & 1 & 1 & 8.27221 & evolves & 17 & 1 & 1 & 0 & 7.27221 & unaffected \\
5 & 3 & 2 & 1 & 7.85717 & triggered & 18 & 1 & 1 & 0 & 7.27221 & tweeted \\
6 & 3 & 1 & 2 & 7.85717 & organization & 19 & 2 & 1 & 1 & 7.27221 & true \\
7 & 6 & 2 & 4 & 7.53524 & wars & 20 & 1 & 1 & 0 & 7.27221 & trajectory \\
8 & 1 & 1 & 0 & 7.27221 & wolf & 21 & 1 & 1 & 0 & 7.27221 & tough \\
9 & 1 & 0 & 1 & 7.27221 & whatever & 22 & 1 & 0 & 1 & 7.27221 & taking \\
10 & 1 & 0 & 1 & 7.27221 & weighted & 23 & 1 & 1 & 0 & 7.27221 & survive \\
11 & 1 & 1 & 0 & 7.27221 & volume & 24 & 1 & 0 & 1 & 7.27221 & surpluses \\
12 & 1 & 1 & 0 & 7.27221 & upcoming & 25 & 1 & 1 & 0 & 7.27221 & stunting \\
13 & 1 & 1 & 0 & 7.27221 & unwanted & & & & & & \\
\hline
\end{tabular}

Table 4. List of collocations of "trade" in The Wall Street Journal.

\begin{tabular}{|c|c|c|c|c|c|c|c|c|c|c|c|}
\hline Rank & Freq & Freq (L) & Freq (R) & Stat & Collocate & Rank & Freq & Freq (L) & Freq (R) & Stat & Collocate \\
\hline 1 & 2 & 1 & 1 & 7.43840 & generate & 14 & 2 & 1 & 1 & 6.43840 & vicious \\
\hline 2 & 2 & 1 & 1 & 7.43840 & embroiled & 15 & 2 & 1 & 1 & 6.43840 & until \\
\hline 3 & 5 & 3 & 2 & 7.17537 & effects & 16 & 2 & 1 & 1 & 6.43840 & united \\
\hline 4 & 3 & 1 & 2 & 7.02336 & flows & 17 & 2 & 1 & 1 & 6.43840 & unending \\
\hline 5 & 19 & 1 & 18 & 6.51640 & war & 18 & 3 & 2 & 1 & 6.43840 & turbulent \\
\hline 6 & 3 & 0 & 3 & 6.43840 & zone & 19 & 3 & 1 & 2 & 6.43840 & try \\
\hline 8 & 1 & 0 & 1 & 6.43840 & wore & 21 & 1 & 1 & 0 & 6.43840 & trigger \\
\hline 9 & 2 & 1 & 1 & 6.43840 & window & 22 & 1 & 0 & 1 & 6.43840 & today \\
\hline 10 & 1 & 0 & 1 & 6.43840 & widening & 23 & 1 & 0 & 1 & 6.43840 & ticks \\
\hline 11 & 1 & 0 & 1 & 6.43840 & weighing & 24 & 1 & 1 & 0 & 6.43840 & thornier \\
\hline 12 & 1 & 1 & 0 & 6.43840 & weakness & 25 & 1 & 1 & 0 & 6.43840 & thaw \\
\hline 13 & 1 & 1 & 0 & 6.43840 & wars & & & & & & \\
\hline
\end{tabular}

\subsection{Different Ideologies and the Construction of National Image of Sino-U.S. News Reports}

The concordance lines of "Trade war" are retrieved to analyze the ideologies and the construction of national image of Sino-U.S. news reports. By analyzing the text through the concordance, the emotional attitude and linguistic features can be displayed. According to the results of Table 5 and Table 6 , it can be found that there are 35 concordance lines containing trade wars in China Daily Corpus, 8 of which show obvious negative semantics, 9 concordance lines show obvious positive semantics, and the rest are neutral. There are 18 concordance lines that contain trade wars in The Wall Street Journal Corpus. Among them, there are 11 concordance lines that show obvious negative semantics, 3 lines that obviously show positive semantics, and the rest are neutral.

Table 5. Concordance line of "trade war" in China Daily's reports.

\begin{tabular}{ll}
\hline Hit & KWIC \\
\hline 1 & Trade war a distraction from volatility of Trump policies \\
2 & growth of the Chinese economy by launching a trade war against China. But despite its efforts the \\
3 & for them and further exacerbating an unnecessary trade war, American debt shadows all of this, but \\
4 & among farmers has remained strong throughout the trade war, and extra money in their pockets will \\
5 & unches and they are happening, independent of the trade war, and our job is to make sure \\
6 & year will crucially depend on the Sino-US trade war and producer price developments. If, as we \\
7 & a silver lining for China, because the US' trade war and technology blockade will help remove the \\
8 & on "improving headlines regarding the US-China trade war" as stocks "priced rising optimism regarding a \\
9 & Journal on July 15, 2019, pinpointed the Sino-US trade war as the main reason behind China's \\
10 & the year, but to what extent has the trade war been a drag on China's economy? \\
11 & US dollar (s) in agricultural goods before the trade war began in 2017." Despite the apparent lack of \\
12 & economic textbooks are correct, and the China-US trade war caused pointless and unnecessary losses on both \\
13 & -US trade conflict evolves into an all-out trade war; China will still be able to accomplish \\
14 & as vehicles and cell phones. The China-US trade war, despite often occupying news headlines, is only \\
15 & to stabilize despite trade war. The US-triggered trade war has hurt China's exports, increased uncertainty \\
\hline
\end{tabular}




\begin{tabular}{ll}
\hline Hit & KWIC \\
\hline 16 & like trade wars, and I hope this trade war is over soon," he said. "This is \\
17 & He said the US has forced an unwanted trade war on China. and China has to take \\
18 & market overestimated the impact of the Sino-US trade war on China and overreacted. China's external \\
19 & percent from around 10 percent, the impact of the trade war on the Chinese economy will be limited. \\
20 & the property sectors. And since the US-China trade war seems likely to last longer, Chinese policymakers \\
21 & Those activities are really unaffected by the trade war," Steve Mollenkopf, CEO of Qualcomm, said during \\
22 & challenges the world. True, by launching a trade war, the US has challenged China. But it \\
23 & China's economy to stabilize despite trade war. The US-triggered trade war has hurt \\
24 & damage as a result of the Sino-US trade war. This is because China has a huge \\
25 & of Trump policies There is nothing like a trade war to deflect public sentiment and focus anger \\
26 & to scrutinize the deal or ask if the trade war was worth it. Many people feel it \\
27 & chicken, it is a shame that the destructive trade war went on as long as it did. \\
28 & time, and hope that those things survive the trade war, whatever happens there," Mollenkopf added. \\
29 & lining exports and rising uncertainty, due to the trade war, will also likely keep corporate investment \\
30 & the US economy rising a global slowdown, a trade war with China, a nervous stock market the \\
31 & president Donald Trump, the presumptions behind his trade war with China are a convenient untruth. Trump \\
32 & ratcheting up tariffs in his ongoing unilateral trade war with China. While the Amazon fires and \\
33 & It is a major reason for picking a trade war with China. Laurence Brahm is the founding \\
34 & be higher: On one trajectory is a costly trade war with the realistic potential for extensive \\
35 & No stunting growth trade war with the US will have limited impact \\
\end{tabular}

Table 6. Concordance line of "trade war" in The Wall Street Journal's reports.

\begin{tabular}{ll}
\hline Hit & KWIC \\
\hline 1 & at the far-reaching impacts of the trade war. Agriculture U.S. farmers took the \\
2 & in place before the start of the trade war between the U.S. and China, \\
3 & that the tariffs and uncertainty about the trade war could trigger or exacerbate an economic \\
4 & them on to U.S. buyers. The trade war, coupled with a slowing global economy \\
5 & the long-term implications of an unending trade war. Large companies fear losing access to \\
6 & big preoccupation on the risk of a trade war linked to trade tensions between the \\
7 & farmers to bear the brunt of a trade war. President Obama had eight years in \\
8 & at less than 1\%. Despite market concerns, the trade war's impact on U.S. growth \\
9 & A Trade War's Vicious Cycle. Tariffs Dent the \\
10 & Korea Feels Bum from Trade War South Korean stocks are among the \\
11 & U.S., China Ramp Up Trade War Stocks, Bond Yields Fall Sharply As \\
12 & Trade War Takes a Muted Toll on U \\
13 & slowest pace in about three decades. The trade war-which called into question the fundamentals \\
14 & largely unscathed by two turbulent years of trade war with China, economic indicators show. Yet \\
15 & is slowing and the impact of the trade war with the United States. The trends \\
16 & by The Wall Street Journal. A protracted trade war with the U.S. has dented \\
17 & be needed now, particularly as China's trade war with the U.S. threatens to \\
18 & continue raising interest rates. Instead, as the trade war wore on, the administration began imploring \\
\hline
\end{tabular}

It can be found from Table 5 that China Daily clarified the position of China and objectively presented the trade war. From "deflect public sentiment and focus anger", "distraction from volatility of Trump policies", it can be found that the reason for Trump's provoking trade war is not only because China has a large trade surplus with the United States, but also Trump wants to use trade war to transfer the attention of public, indicating that trump wants to expand debt of the United States to solve political problems. The Chinese media employs "exacerbating an unnecessary trade war", "caused pointless and unnecessary losses", "unwanted trade war", "Chinese economy will be limited", "hurt China's export", "it's a shame that the destructive trade war" these negative words to illustrate that the trade dispute has brought great losses to the economy of China and the United States. China did not support the trade war and emphasized that this trade war is unnecessary. "Trade war seems likely to last long" shows that this trade negotiation has always failed to reach an agreement that satisfies both parties, and this invisible trade war will continue for a long time. "Farmers, agriculture goods, technology" very clearly points out that the main areas of the trade war are agriculture and technology, and both China and the United States have suffered a certain degree of loss in foreign trade in these two areas. "Rising a global slowdown" and "challenge the world" show that the war provoked by the United States has affected the economic development of world. Chinese media uses positive words such as "silver lining for China", "China's economy to stabilize", "China will still be able to accomplish", "overestimated the impact of the Sino-U.S. trade war on China", "no stunting growth", "limited 
impact" to show that the impact of the trade war on China is not as great as expected and indicate the confidence of Chinese people in defeating the trade war. At the same time, it also shows China's optimistic and positive attitude towards the trade war. China is ready and able to deal with it, constructing a positive and responsible Chinese image and a self-confidence and self-improvement spirit.

From Table 6, we can find that the American media basically describes the harm caused by the trade war, and also truthfully reports the process of the Sino-U.S. trade war. From "farmers to bear the brunt of a trade war" and "large companies fearing access to", we can find that trade war has a great impact on farmers and enterprises, which reflects that trade war has a certain damage to the U.S. economy. At the same time, it reflects the real situations and attitudes of the American and constructs the image of the victims of the American. However, The Wall Street Journal also employs "largely unscathed by two turbulent years of trade war with China" to express that the U.S. economy has not been greatly affected. To some extent, America used the data to give the American people confidence in the trade war, stabilize the national situation, and highlight their strong attitude to trade disputes. From "Korea feels burn from trade war", we can find that the American media pays close attention to South Korea. It indicates the alliance between the United States and South Korea. Therefore, South Korea also suffered heavy losses in this trade war. "Coupled with a slowing global economy" shows that the trade war has a great impact on the global economy.

In order to further study the views of Chinese and American media on both sides, we retrieve The Wall Street Journal Corpus and China Daily Corpus again. We focus on the concordance lines of "trade" and "China". Due to the large number of concordance lines, we randomly select a few of them for analysis.

Example (1): President Trump's trade strategy has exposed China's vulnerability, demonstrating the risks of going toe-to-toe with a determined opponent that happens to be your largest customer. (The Wall Street Journal, 2019.01.10)

Example (2): Its attempt to strangle the development of Chinese technology companies is meant to block China's advancement in science and technology. Likewise, the U.S. is seeking to contain the growth of the Chinese economy by launching a trade war against China. But despite its efforts the U.S. will not be able to contain China's technological progress, nor will it halt China's economic development. (China Daily, 2019.05.10)

Example (1), mainly reports that Trump's trade policies has hit China. It strengthened the confidence of the American people and at the same time created a firm and powerful image of the United States. From this, it can be clearly seen that the mainstream American media has a clear ideological tendency when reporting on the "trade war". It tends to maintain the positive image of the United States.

In Example (2), by reporting on the conversation between Foreign Minister Wang Yi and the U.S. Secretary of State, it clearly shows that no matter how the United States suppressed
China, it could not impede the development of China. It constructs China as an image of advancing bravely in the face of difficulties.

Example (3): Did he and the Democrats in Congress make any progress in curtailing China's intellectual property theft and mercantilist policies that threatened U.S. high-tech and basic industries vital to national security? (The Wall Street Journal, 2019.03.18)

Example (4): "I think it goes without saying that we spend a lot of time helping and supporting the deployment now of $5 \mathrm{G}$ in China. So, we want to make sure that happens. Those activities are really unaffected by the trade war," Steve Mollenkopf, CEO of Qualcomm, said during a media briefing Monday. (China Daily, 2019.09.28)

Example (3): shows that Obama and the Democrats took tough measures against China during his tenure, emphasizing the hard-line attitude of the U.S. two parties towards high-tech intellectual property.

Example (4) shows the rapid development of technology in China through the words of the CEO of Qualcomm. The birth of $5 \mathrm{G}$ has made the Chinese market occupy an important position in the United States. This shows the strength of China in science and technology, and also shows the importance of Chinese technology for the development of foreign companies.

Example (5) Tariffs are hurting China (and the U.S., too, but less so). One of the best things that could happen for China is a Trump defeat in 2020. (The Wall Street Journal, 2019.03.18)

Example (6) The first factor is the difference in China's win-win policy and the U.S.'s hegemonic policy. China has always advocated fair cooperation and mutual benefit. But Washington insists on following an "America first" policy by implementing unilateral and protectionist measures against its trading partners, even against its allies. (China Daily, 2019.06.29)

In Example (5), the United States has misunderstood the position of China. It can be found from Example (6) that China always upholds to the path of peaceful development, and regards peaceful coexistence and mutual benefit as diplomatic principles. Because of the misjudgment of China's position by the American media, it has misled its own public opinion and international public opinion.

Based on the above analysis of the text and the formation of discourse, we explore the deeper social and cultural practices of the two countries. In terms of economy, the United States has had a huge trade deficit with China in recent years. American society believed that this was the main reason for the U.S. trade deficit and unemployment rate. Therefore, The Wall Street Journal proved the rationality of Trump's trade policy with China and endowed the current Sino-U.S. trade relationship with the characteristics of competition. On the contrary, China Daily denied the trade policy and presents a positive image of China. In terms of society, both countries place an important position on building a good image of the country. China emphasized that it is necessary to strengthen friendship and cooperation with other countries on the basis of adhering to the Five Principles of Peaceful Coexistence, and to 
establish a new type of international relations in a way of mutual respect, fairness, justice, and win-win cooperation. While the United States pays more attention to its own economic interests and international status.

\section{Conclusion}

The paper built a comparative corpus of Chinese and Western media on "Sino-U.S. trade war", using high-frequency words, collocations and concordance lines to analyze the reports of Sino-U.S. trade war by Chinese and American media. It is found that the linguistic features of the media reports on Sino-U.S. trade disputes reveals the different focuses and attitudes of the two countries, reflects the different ideologies of the two countries, and constructs different national images. The Wall Street Journal and China Daily reported truthfully on the progress and harm of the Sino-U.S. trade war. However, the overall coverage of The Wall Street Journal emphasizes the economic impact of the Sino-U.S. trade war on its own country and the global economy. Although China Daily has also rendered the dangerous atmosphere of the trade war, the focuses are China's attitude and response to trade war, and it is committed to developing relations on the basis of non-conflict, mutual respect, and win-win cooperation. In terms of building a national image, The Wall Street Journal uses more positive words to construct the United States as an image of strong and just. China Daily builds China as an image of a big country that actively responded to challenges and actively promoted global free trade and peaceful coexistence.

In summary, by combining the qualitative analysis of critical discourse with the quantitative analysis of corpus, readers can improve their ability to discover the ideologies implied in the report and they can be more objective and rational to view the events described in the news report. The method also enables readers to clarify the relationship between language and the power and consciousness behind the language, revealing public opinion orientation and political stance. However, this research still has some limitations. For example, self-built corpus is time-consuming and laborious, our corpora are not large enough, which may affect the universality of the results. Secondly, only two medias were selected from China and the United States, and the number of selected media is small and the result may not sufficiently representative. Therefore, more data from more medias can be studied in future research.

\section{Acknowledgements}

This study was supported by Hunan Social Science Fund of China (Grant No. 19ZDB008), Scientific Research Project of Hunan Provincial Department of Education (Grant No. 19A105 and No. 19C0484).

\section{References}

[1] Ge Lisha. A Corpus-based Critical Discourse Analysis of Chinese and American Terrorist Reports. Journalism Research Guide, 2018, 9 (22): 44-45+92.

[2] Fowler, R., Hodge, B., Kress, G. \& Trew, T. Language and control. London /Boston /Henley: Routledge \& Kegan Paul, 1979.

[3] Fairclough, N. Discourse and social change. Cambridge: Polity Press, 1992.

[4] Wodak, R. \& Reisigl, M. The Discourse-Historical Approach. In Wodak, R., \& Meyer, M. (Eds). Methods for Critical Discourse Analysis. Beijing: Peking University Press, 2009.

[5] Van Dijk, T. A. Critical discourse studies: A sociocognitive approach. In Wodak R\& Meyer M. Methods of Critical Discourse Analysis. (2nd ed). Beijing: Peking University Press, 2009.

[6] Widdowson, H. G. Discourse analysis: a critical view. Language and Literature, 1995, 4 (3), 157-172.

[7] Hardt-Mautner, G. Only connect: Critical Discourse Analysis and corpus linguistics. Lancaster: University of Lancaster, 1995.

[8] Baker, P., Gabrielatos, C., McEnery, T. Discourse analysis and media attitudes. Cambridge: Cambridge University Press, 2013.

[9] Yang Huizhong. Introduction to Corpus Linguistics. Shanghai: Shanghai Foreign Language Education Press, 2002.

[10] Liu Ning. A corpus-based comparative study of Chinese and American media reports on Chinese smog-From the perspective of Critical Discourse Analysis. Journal Beijing International Studies University, 2018, 40 (5): 37-53.

[11] Baker, P., Gabrielatos, C., KhosraviNik, M., Krzyżanowski, M., McEnery, T., \& Wodak, R. Combining critical discourse analysis and corpus linguistics to examine discourses of refugees and asylum seekers in the UK press. Discourse \& Society, 2008, 19 (3), 273-306.

[12] Bednarek, M., Caple, H. Towards a new methodological framework for analyzing news discourse in Critical Discourse Analysis and beyond. Discourse \& Society, 2014, 25 (2): 135-158.

[13] Chang Baoli. Critical Discourse Analysis of American Hegemonic Diplomacy from the Perspective of Systematic Functional Grammar. Journal of Bengbu University, 2019, 8 (6): 59-63.

[14] Zhang Junchen. A Corpus-based Critical Discourse Analysis starting with the English news report of US President Trump's visit to China in 2017. Education Media Research, 2019 (3): $72-78$.

[15] Stubbs, M. Text and corpus analysis. Oxford: Blackwell Pubilshers, 1996. 